\title{
Alma Ata Declaration and Malaria Prevention: Ten Years Narrative Review of landmark Achievement on Use of Insecticide Treated Nets (ITNS) Among Pregnant Mothers and Children Under Five in Nigeria
}

Odoko JO $\mathrm{O}^{1,2^{*}}$, Nwose $\mathrm{EU}^{1,3}$, Nwajei $\mathrm{SD}^{1}$, Agege $E A^{1}$, Moyegbone $\mathrm{JE}^{1}$, Akuirene $O A^{1}$ and Igumbor $E O^{1}$

${ }^{1}$ Department of Public and Community Health, Novena University Ogume, Nigeria

${ }^{2}$ Bayelsa State College of Health Technology Otuogidi-Ogbia, Nigeria

${ }^{3}$ School of Community Health, Charles Sturt University, New South Wales, Australia

\begin{abstract}
Abstract: Malaria epidemiology in Nigeria is still at a concerning rate. Health promotion is fundamental in primary healthcare (PHC) and one of the components is the prevention of endemic diseases, which include the use of insecticide treated nets (ITNs), provided free and Roll Back Malaria (RBM) programs. The objective of this study is to narratively review the ten years landmark achievement of Alma-Ata declaration on the use of ITNs among pregnant mothers and under-five children between 2009 and 2019 in Nigeria, including the RBM target and geopolitical zones' performances.
\end{abstract}

\begin{abstract}
Methods: This non-systematic review study selected 50 studies on epidemiology on malaria, PHC, health promotion and Alma-Ata declaration on use of ITNs from literature searched. Search bases included Google Scholar, while inclusion were peer reviewed journals and governmental documents.
\end{abstract}

Results: ITNs ownership and utilization in the geographical zones of Nigeria are unequal since 2010. By 2019, Nigeria household ownership of at least one ITNs was $55 \%$, which is short of the $80 \%$ RBM targeted since 10-years ago. Reduction in prevalence of malaria is strongly associated with baseline knowledge of the disease $(p<0.0001)$; while level of nonutilization of ITNs in 2010 is positively correlated to improvement in ownership in 2019 ( $p<0.03$ ).

Conclusion: Achievement of Alma-Ata declaration in the availability of ITNs has yet to reach the RBM target and there is indication of backsliding. There is need to reactivate and sustain health promotion programs on ownership and utilization of ITNs at the community level.

Keywords

Alma- Ata Declaration, Health promotion, Financing, Primary health care, Distribution of nets

\section{Introduction}

\section{Overview of epidemiology}

Comprehensive primary health care is linked to the conference of Alma-Ata organized by United Nations on PHC in 1978 to achieve health for all by $2000[1,2]$. The Alma-Ata conference considered PHC as the main plan of action [3]; and the declaration defined educating the public on the prevention and control of health problems and encouraging participation, prevention and control of locally endemic diseases, maternal and child health care including family planning, as part of the eight components of PHC [4]. This study is a continuation of epidemiology and primary healthcare narratives on malaria issue.
Epidemiologically, the impact of malaria on the world population is constantly being reviewed by the World Health Organization (WHO), albeit yearly. As reported in 2011 and

*Corresponding author: Dr. Odoko JO, Department of Public and Community Health, Novena University Ogume, Delta State Nigeria. Tel: +234-8034918516

Accepted: May 04, 2021

Published online: May 06, 2021

Citation: Odoko JO, Nwose EU, Nwajei SD, et al. (2021) Alma Ata Declaration and Malaria Prevention: Ten Years Narrative Review of landmark Achievement on Use of Insecticide Treated Nets (ITNS) Among Pregnant Mothers and Children Under Five in Nigeria. Ann Public Health Reports 5(1):193-200 
Citation: Odoko JO, Nwose EU, Nwajei SD, et al. (2021) Alma Ata Declaration and Malaria Prevention: Ten Years Narrative Review of landmark Achievement on Use of Insecticide Treated Nets (ITNS) Among Pregnant Mothers and Children Under Five in Nigeria. Ann Public Health Reports 5(1):193-200

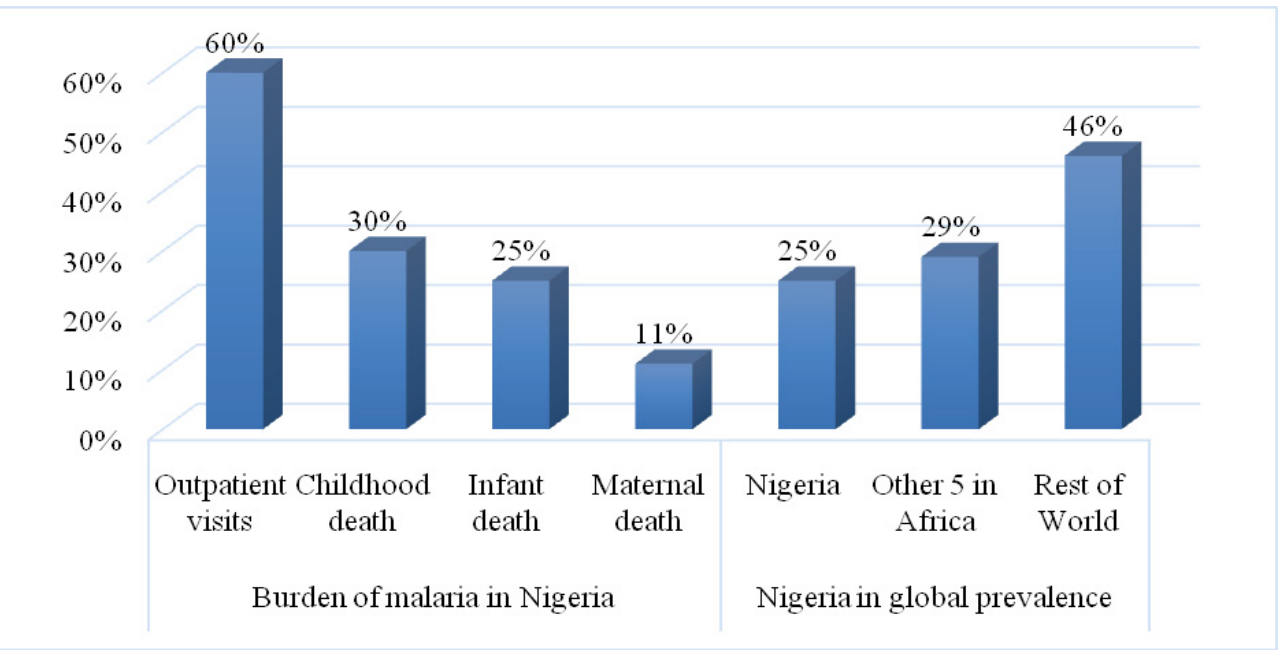

Figure 1: Attributions of malaria burden and prevalence in Nigeria $[5,10]$.

a recent narrative review [5], there are consistent reports that Nigeria contributes the highest proportion of malaria incidents relative to other countries (Figure 1). Therefore, while there have been several studies on malaria at different localities [6-9], there is on-going need to evaluate landmark achievements.

Nigeria has six geopolitical zones and while the southern part has climate more amenable to malaria vector, the north is not immune due to multiple environmental factors [11]. It is estimated that only $3 \%$ of Nigerians live in the highlands free of malaria. Further, Malaria Indicator Survey (MIS) of 2010 shows that the South West zone with least percentage of ITNs ownership did not have the highest prevalence of malaria among children [10]. Therefore, first of two objectives of this evaluation of achievement in malaria elimination needs to compare geopolitical zones.

\section{Primary health care perspective in use of ITNs to prevent Malaria}

The first International Conference on Health Promotion held in-Ottawa in 1986 was built on progress made on PHC, the WHO Targets for Health for All by 2000 and beyond. The conference identified health promotion as a process of enabling people to increase control over, and to improve their health [12]. The declaration defined the components of PHC to include maternal and child health $(\mathrm{MCH})$ as well as health education and control of local diseases, amongst others [4].

Nigeria developed strategic plan to create awareness on prevention of malaria in pregnancy through the use of insecticide treated nets ITNs [14]. Pertinent PHC reforms have occurred over the past three decades including prior to Alma-Ata declaration of PHC in 1978 (Table 1), as Nigeria had set the ball rolling with the implementation of Basic Health Services Scheme (1975-1980). In 1992, Nigeria commenced $\mathrm{PHC}$ programs in the local government areas, which included the Integrated Management of Childhood IIIness (IMCI), Integrated Maternal Newborn and Child Health (IMNCH), Maternal Newborn and Child Health Week (MNCHW) and the Im-
Table 1: Pertinent PHC reforms in Nigeria over the past three decades $[8,13]$.

\begin{tabular}{|l|l|}
\hline Period & Event \\
\hline 2009 & 5-years (2010-2015) development/strategic plan \\
\hline $2004-2007$ & Health sector reform \\
\hline 2000 & RBM's 80\% target of ITNs ownership by year-2010 \\
\hline $1999-2004$ & National Health Insurance \\
\hline 1998 & Launch of National Health Policy \\
\hline 1996 & National malaria control policy \\
\hline 1986 & Adoption of Models for PHC \\
\hline $1975-1980$ & Basic Health Service Scheme \\
\hline
\end{tabular}

munization Plus Days (IPDs) [15]. The Central part of Nigeria showed widespread coverage of ITN achieved through mass drug administration campaign [16].

Roll Back Malaria (RBM) meeting was convened for African Heads of States in 2000 resulting in the Abuja Declaration, which set targets for major malaria interventions of $80 \%$ coverage by $2010[17,18]$. The Abuja Declaration advocated all member states to promote community participation in joint ownership and control of RBM actions, especially as achievements and challenges were been observed $[18,19]$. Studies report of a rise in use of ITNs in sub-Saharan Africa due to international funding for malaria control among pregnant and children $[20,21]$. Therefore, the second objective of this landmark review is to articulate how this set target of RBM has been achieved.

It is imperative to note that recognition of the unacceptable mortality and morbidity from malaria in Africa led to the formation of the RBM initiative and Abuja Declaration to halve the burden of malaria and its associated death by 2010 . What this review advances is the concept of PHC [7,15,22], with a focus on strategies to sustain malaria prevention. With particular reference to malaria issue in South-South Nigeria, previous review has indicated the need for health promotion among all stakeholders on use of ITNs [13]. In line with the 
Citation: Odoko JO, Nwose EU, Nwajei SD, et al. (2021) Alma Ata Declaration and Malaria Prevention: Ten Years Narrative Review of landmark Achievement on Use of Insecticide Treated Nets (ITNS) Among Pregnant Mothers and Children Under Five in Nigeria. Ann Public Health Reports 5(1):193-200

first objective, this review aims to assess how the zones compares with each other in terms of ownership of ITNs.

\section{Health promotion concept: Utilization of ITNs}

Health promotion, is the process of raising people control to improve health in their everyday life $[12,23]$. The Ottawa Charter on health promotion motivated health and social wellbeing of individuals and families $[12,24]$. Health promotion includes placing health and the agenda of all stakeholders to accept responsibilities on health. Health care responsibilities are divided among individuals, community groups, health professionals, health service institutions and governments [12]. Health promotion concept has been adopted by WHO in the prevention of malaria through promotion of ITNs [25-27].

Nigeria has a National Strategic Plan for Malaria Control [8], and one of the plans is to promote the use of ITNs by mass media campaigns [14]. This plan for promotion remains imperative, especially given the impact of perception. Preliminary study from the South-South Nigeria showed that among the households that owned ITNs, about $69 \%$ of individuals did not use ITNs every day [28]. Another report indicated perceptions about chemicals used in treating the ITNs and low risks among adolescents [29].

Similar concerns abound across the tropical countries including Uganda and Kenya [30-33]. There is a wrong belief that pregnant and non-pregnant adolescents do not need malaria prevention. In addition, health workers have poor communication skills in the communities resulting to low utilization of health facilities and in education on malaria prevention. Therefore, health promotion programs are unequivocally advanced as an option to address the malaria problem [34-36]. Hence the third objective is to evaluate the level of correlations in landmark achievements.

\section{Objective of review}

This study aims to narratively review the recent ten years' landmark achievement of Alma-Ata declaration on the use of ITNs among pregnant mothers and under-five children between 2009 and 2019 in Nigeria, including the Roll Back Malarial (RBM) target and geopolitical zones' performances vital to health promotion. The main objective is to critically assess and evaluate some available literatures that address the public health issue of ITNs in terms of progress in Nigeria.

\section{Methods}

A non-systematic approach was adopted, due to no outcome when all relevant search phrases were applied systematically notably on PubMed. Literature search terms included epidemiology of malaria, primary health care, and health promotion; as well as background trios Alma-Ata declaration, ITNs and Nigeria.

Exclusion and inclusion criteria: The initial search engine for review articles were google scholar and google. Afterwards selection was limited to reputable sources such as peer-reviewed journal articles including from PubMed and World Health Organization as well as governmental materials.
For instance, in attempted systematic review using PubMed, ITNs yielded 835 articles. Add-on 'Nigeria' resulted in 88 articles; outcome was zero [0] with further add-on of 'Alma Ata'. Based on the non-systematic method, a total of 52 studies were reviewed. Main areas focused were:

1. How does the South-South zone of Nigeria compares with other zones in terms of ownership of ITNs?

2. How has the set target of RBM been achieved?

After excluding article were not peer-reviewed, and not authoritative government documents, the numbers of articles selected from the search themes were:

$>$ Primary healthcare $=12$

Health promotion on ITNs $=10$

$>$ Review of 10 years mark achievement $=7$

$>$ Pregnant women $=6$

$>$ Under five years children $=6$

$>$ South-South Nigeria $=3$

$>$ Alma-Ata declaration $=2$

Critical review included descriptive comparisons of data that reported ITNs ownership and prevalence of malaria for 2010 with 2019. Further review was correlation analysis to evaluate associations for improvements in ITNs ownership and reduction on malaria prevalence. Both the correlation evaluation and descriptive comparison were performed using Excel Analysis tool PAK on Microsoft Office 365 ProPlus.

\section{Results}

\section{Malaria monitoring outcomes}

The prevalence of malaria in Nigeria was reduced from $42 \%$ in 2010 to $27 \%$ in 2015 and $23 \%$ in 2018 [37] and the reduction is due to improvements in possession of ITNs from $8 \%$ in 2008 to $69 \%$ in 2015 . Drop in prevalence of malaria due to effective intervention depicts that Nigeria is in the malaria control phase, but yet to move into elimination phase [38]. Of interest is the observation that the geopolitical zone (SouthSouth), which is one of the zones most prone to malaria has the least percentage ITNs ownership in the urban areas. Among the three southern zones, the South-South appears to have highest proportions of ITNs owners and users, but has also marginally highest in prevalence of malaria.

Southern part of the country has climatic condition more amenable to mosquito survival and hence malaria infestations [11]. The results show that ITNs ownership and utilization of ITNs are unequal between any two zones. While both measures are lower in the south compared to the north (Table 2), improvements are more in the southern (Figure 2). Comparing the report of 2019 on possession of ITNs with that of 2010 survey in Table 1, it is evident that relative improvement has been unequal (Figure 2).

Further, evaluation of malaria incidence for improvement showed and averaged better in the north (25\%) than the south (21.2\%). The South West zone showed greatest re- 
Citation: Odoko JO, Nwose EU, Nwajei SD, et al. (2021) Alma Ata Declaration and Malaria Prevention: Ten Years Narrative Review of landmark Achievement on Use of Insecticide Treated Nets (ITNS) Among Pregnant Mothers and Children Under Five in Nigeria. Ann Public Health Reports 5(1):193-200

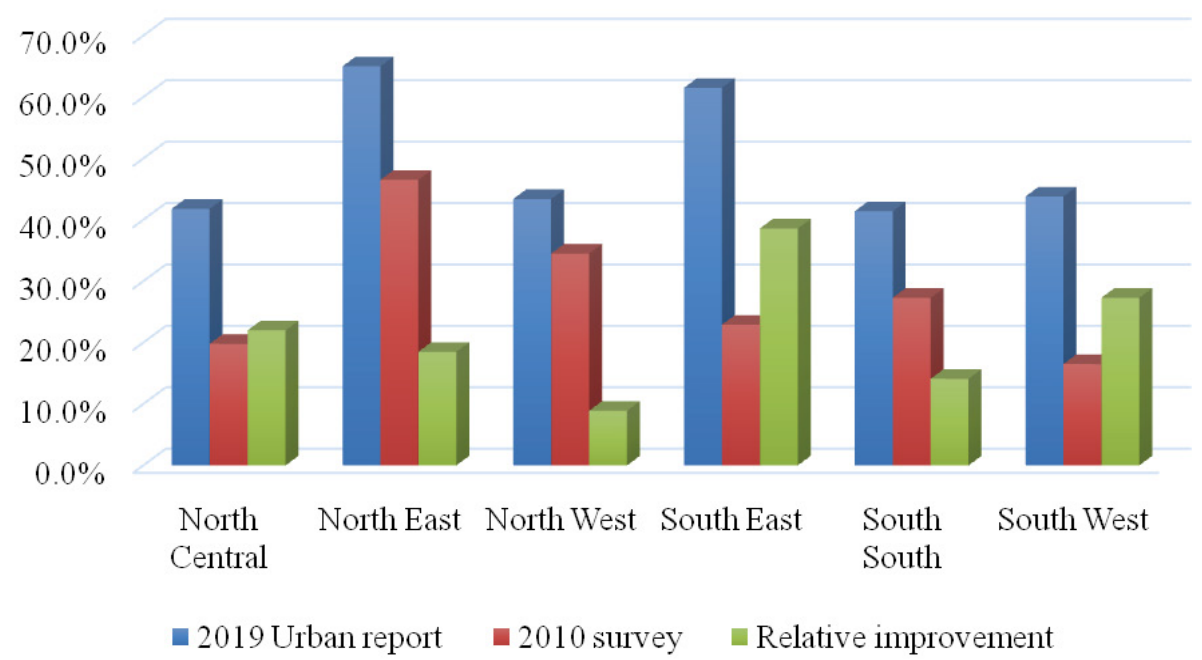

Figure 2: Comparison of ownership of ITNs between 2010 [10], and 2019 surveys [40].

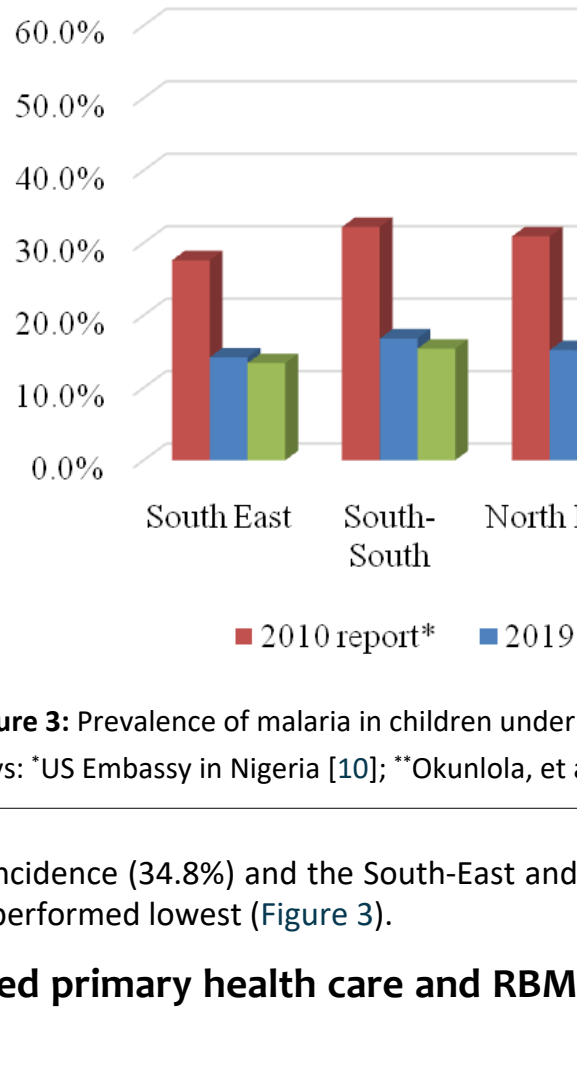

Alma Ata declaration is a grass root concept of rendering primary health services [15]. To improve health care delivery, Nigeria and other Africa Countries adopted a policy to raise the number of people utilizing ITNs to $60 \%$ by 2005 [41]. Despite funding on PHC, government incentives (e.g. provision of basic social amenities) to motivate healthcare, acceptance of job postings to the rural regions is limited. Health promotion, preventive, and PHC interventions are low with the universal health service coverage index [11]. Two key programs that have been developed for PHC involving malaria prevention were:
2014: National health Act// Basic Minimum Package of health Services (BMPHS)

2012: Free maternal and child health program implemented in some states

Nigeria implemented policies on Millennium Development Goals, an off shoot of Alma-Ata declaration on PHC and health for all by 2000. The end report of this program in 2015 indicated reduction of maternal and child mortality, as well as the spread of malaria and improved access to safe drinking water [42]. It has been recommended that Nigeria should continue to sustain the health programs in partnership with the sustainable development Agenda of 2030 [43].

The Federal Ministry of Health developed a 5-year National Strategic Plan for Prevention and Control of Malaria in 2009 (Table 1). The vision was a malaria-free Nigeria, with increase 
Citation: Odoko JO, Nwose EU, Nwajei SD, et al. (2021) Alma Ata Declaration and Malaria Prevention: Ten Years Narrative Review of landmark Achievement on Use of Insecticide Treated Nets (ITNS) Among Pregnant Mothers and Children Under Five in Nigeria. Ann Public Health Reports 5(1):193-200

ownership and use of ITNs. A significant achievement in control of malaria in Nigeria is the reduction of prevalence of malaria cases from $42 \%$ in 2010 to $27.4 \%$ in 2015 . This success is attributed to increased ownership of ITNs from $2 \%$ in 2003 to $8 \%$ in 2008 and $69 \%$ in 2015 . However, there was drop of the ITNs to $61 \%$ in 2018 and to $55 \%$ in 2019. Indeed, there is evidence of gradual decline instead of improvement (Figure 4). Thus in Nigeria, only an average of $60 \%$ households possess ITNs [44-46] and this decline in ownership of ITNs in households resonate with the fears of stall in eliminating malaria globally [47]. Report on the use of ITNs in 2019 revealed 55\% of households possessing at least one mosquito net for sleeping. This results suggest inadequate intervention to eliminate malaria in Nigeria [40].

Since the Abuja Declaration, there has been progress towards increasing the availability of financial resources for health. The use of community based primary health care (CBPHC) and the use of community health workers (CHWs) in malaria control has averted many child deaths than health facility based services $[48,49]$. As part of implementing the

Table 2: Ownership and utilization of ITNs among Nigerian geopolitical zones in 2010 [39].

\begin{tabular}{|l|l|l|l|}
\hline Zone & Ownership $^{*}$ & Utilization $^{\ddagger}$ & Non-Users \\
\hline North Central & $19.80 \%$ & $14.20 \%$ & $5.60 \%$ \\
\hline North East & $46.50 \%$ & $43.90 \%$ & $2.60 \%$ \\
\hline North West & $34.50 \%$ & $31.50 \%$ & $3.00 \%$ \\
\hline South East & $22.90 \%$ & $12.70 \%$ & $10.20 \%$ \\
\hline South- South & $27.30 \%$ & $21.40 \%$ & $5.90 \%$ \\
\hline South West & $16.50 \%$ & $8.40 \%$ & $8.10 \%$ \\
\hline
\end{tabular}

*Ownership in households; percentage is lower than reported in the data of US Embassy in Nigeria (2011)

${ }^{\ddagger}$ Previous night utilization
Alma-Ata declaration on PHC, Support to National Malaria Program (SuNMaP) embarks on mass distribution campaign to support states with supply of ITNs to pregnant women [50].

Government's improvement in PHC program since Alma-Ata declaration has resulted in states receiving support for ITNs, however, some minor discrepancies are reported. For instance, the indication of over $70 \%$ of households owning at least one ITNs [8], is uncorroborated with results presented on figure 2. The report of US Embassy in Nigeria (2011) on percentage of household' ITNs ownership at the geopolitical zones in 2010 are higher by average of about $12 \%$ than what Killian, et al (2013), reported for 'urban'.

\section{Critical review of levels of improvement}

A further evaluation of the improvements in ITNs ownership and malaria prevalence among children under 5-years show high levels of correlation. With special focus on SouthSouth Nigeria, it is observed from the report of Okunlola, et al. (2019) that level of improvement in the geopolitical zone on reduction of malaria incidence is better than the country's average (Figure 5).

Further review of WHO data indicate malaria cases in the country has been 25\% in both 2018 and 2019. Reduction in malaria prevalence is more associated with knowledge of incidence created earlier $(R=0.9854 ; p<0.0001)$. Improvement in prevalence is most inversely associated with on-going ownership of ITNs, though no statistical significant difference. Improved in ownership is most inversely associated with existing knowledge of prevalence of malaria, but not statistically significantly different. Percentage of non-utilization of ITNs in 2010 is positively correlated with improvement in ownership of ITNs recorded in 2019 ( $R=0.8659 ; p<0.03)$, which implies health promotion improved utilization (Table 3 ).

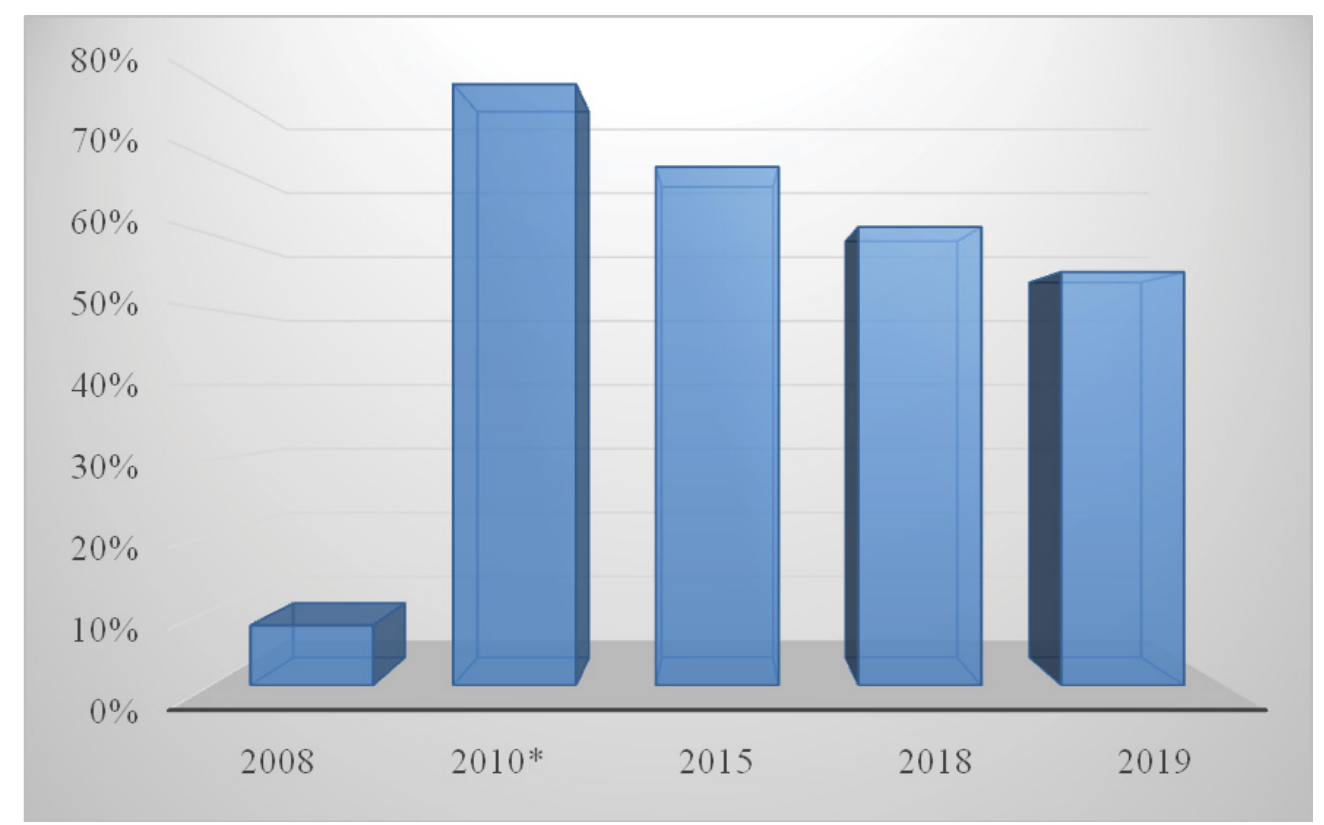

Figure 4: RBM'2010-target vs. 2019-achievement on household possession of ITNs [44]. 
Citation: Odoko JO, Nwose EU, Nwajei SD, et al. (2021) Alma Ata Declaration and Malaria Prevention: Ten Years Narrative Review of landmark Achievement on Use of Insecticide Treated Nets (ITNS) Among Pregnant Mothers and Children Under Five in Nigeria. Ann Public Health Reports 5(1):193-200

Table 3: Pearson correlation showing associations of landmark improvements.

\begin{tabular}{|c|c|c|c|c|c|c|c|}
\hline & $\begin{array}{l}2010 \\
\text { prevalence }\end{array}$ & $\begin{array}{l}2019 \\
\text { prevalence }\end{array}$ & $\begin{array}{l}\text { Prevalence } \\
\text { improvement }^{*}\end{array}$ & $\begin{array}{l}2019 \\
\text { ownership }\end{array}$ & $\begin{array}{l}2010 \\
\text { ownership }\end{array}$ & $\begin{array}{l}\text { Ownership } \\
\text { improvement }\end{array}$ & $\begin{array}{l}\text { ITNs unused in } \\
2010\end{array}$ \\
\hline 2010 prevalence & 1.0000 & & & & & & \\
\hline 2019 prevalence & 0.6625 & 1.0000 & & & & & \\
\hline $\begin{array}{l}\text { Prevalence } \\
\text { improvement }^{*}\end{array}$ & $0.9854^{+}$ & 0.5254 & 1.0000 & & & & \\
\hline 2019 ownership & -0.7171 & -0.7060 & -0.6541 & 1.0000 & & & \\
\hline 2010 ownership & -0.4143 & 0.0100 & -0.4729 & 0.5387 & 1.0000 & & \\
\hline $\begin{array}{l}\text { Ownership } \\
\text { improvement }\end{array}$ & -0.2994 & -0.7356 & -0.1730 & 0.4588 & -0.5014 & 1.0000 & \\
\hline ITNs unused in 2010 & -0.1762 & -0.5647 & -0.0719 & 0.0503 & -0.7720 & $0.8659^{\ddagger}$ & 1.0000 \\
\hline
\end{tabular}

${ }^{*}$ in reduction of malaria prevalence among children under 5 years old; ${ }^{\dagger} p<0.0001 ;{ }^{\ddagger} p<0.03$.

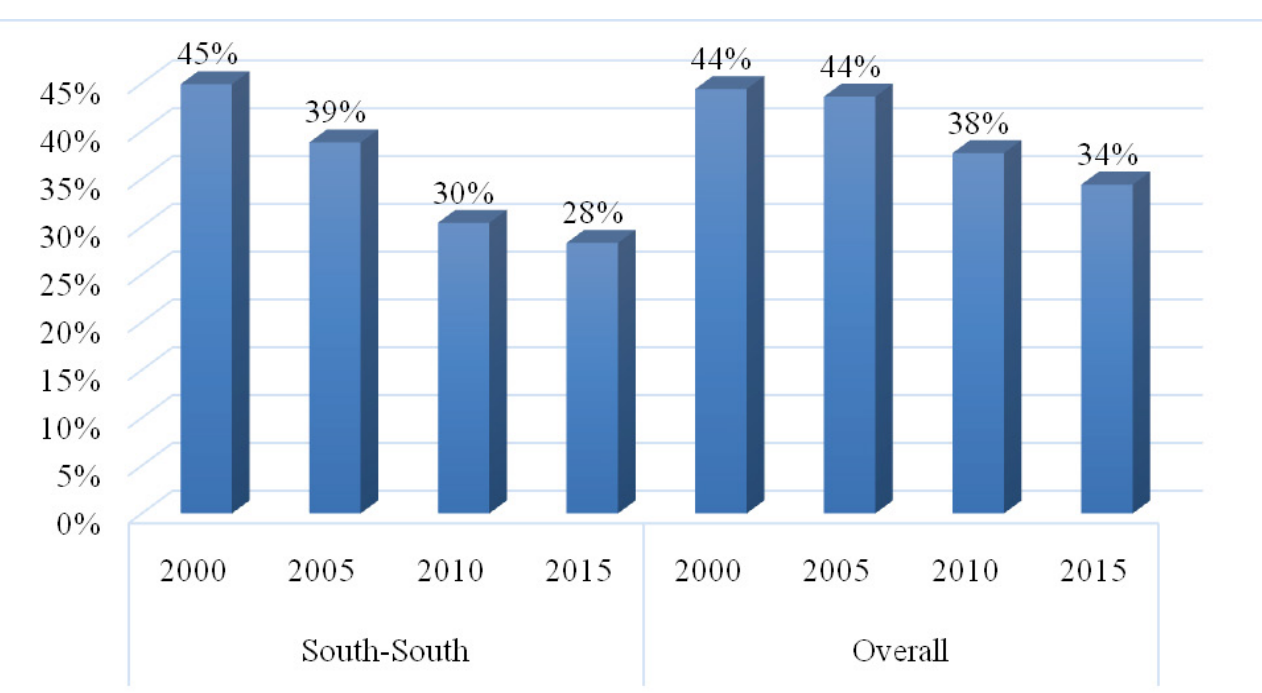

Figure 5: Improvement on reduction of malaria prevalence in South-South vs. country.

\section{Discussion}

The Declaration of Alma Ata highlighted eight elements that form the basis of comprehensive PHC program interventions to achieve health for all. These elements include education, management and prevention programs for prevailing health problems and methods of preventing and controlling them [51]. Also important are promotion of basic sanitation, proper nutrition and safe water, $\mathrm{MCH}$ programs encompassing family planning, immunization against major infectious diseases and appropriate provisions for treatment of common diseases and injuries.

The declaration of Alma-Ata was reinforced in Abuja in 2000 , by African leaders to halve the burden of malaria and its associated deaths by 2010 . One of the first targets was to provide ITNs to pregnant mothers and children under five years to improve the health of the vulnerable population from preventable malaria which causes high rate of deaths. This report highlights the failure of landmark agenda that none of the six geo-political zones of Nigeria has achieved the target of $80 \%$ ownership of ITNs. Although, there is relative varied improvement across country. Although malaria prevalence in the South-South appear to have improved more than the country' average (Figure 5), it is nevertheless worrisome that the geopolitical zone is lowest in ITNs ownership and at about half of a target that should have been achieved 10 -years ago (Figure 2).

Implementation of Millennium Development Goals in Nigeria would fulfill the Alma-Ata declaration on PHC with reduction of $\mathrm{MCM}$ through national and international partnership. Within the period of review, the use of community base PHC and community health workers in malaria control has helped in the mass distribution of nets to rural areas. These health workers have contributed to improving community knowledge on good health seeking behavior in using ITNs to prevent malaria in pregnant mothers and under five years children. In terms of efficacy measured by reduction in incidence of malaria, this report highlights a 2019 report compared with 2010 (Figure 3 and Figure 5). Considering 25\% report of the WHO for Nigeria in 2018 and 2019, the reports indicate landmark achievement.

While there is achievement in reducing prevalence of malaria in children under 5-years old across the country, the 
Citation: Odoko JO, Nwose EU, Nwajei SD, et al. (2021) Alma Ata Declaration and Malaria Prevention: Ten Years Narrative Review of landmark Achievement on Use of Insecticide Treated Nets (ITNS) Among Pregnant Mothers and Children Under Five in Nigeria. Ann Public Health Reports 5(1):193-200

reduction in prevalence is not correlated with improvement with ITNs ownership, but seems to trend with actual prevalence (Figure 4). For instance, in the 2010 report, the SouthSouth zone was not among the top-two with highest ownership of ITNs, but did make up top-to with lowest prevalence of malaria. Based on the 2010 and 2019 reports, evidence is that reduction level in prevalence of malaria across the zones strongly correlates with previous knowledge of prevalence, while non-utilization of the ITNs among owners appear to improve with ownership (Table 3).

Several studies have reported on universal coverage of ITNs distribution and trends in malaria incidence [7,11,36,39] and some have focused on surveillance and factors of utilization $[16,38,40,41]$. It is known that the RBM has yet to be achieved and this report affirms that Nigeria has $55 \%$ household coverage with ITNs and record a decline of malaria incidence since the last 5-years. What is unknown, which this report brings to the fore of discourse is the correlation (and lack thereof) between improvements in ITNs ownership and malaria prevalence with reports of 2010 compared to 2019. The significance to health promotion agenda in pursuit of RBM agenda and PHC improvement is that zones previously doing well in terms of ITNs ownership and malaria prevalence in 2010 have performed less according to 2019 report.

\section{Conclusion}

Primary health programs through the influence of political will have gone a long way in near realization of various target toward achieving the Alma-Ata declaration, especially in RBM. The main aim of Alma-Ata declaration is to extend health care services to individuals through their full participation at a cost that the community can afford. Implementation of WHO recommendation to provide ITNs as part of primary health programs has contributed to the reduction of $\mathrm{MCH}$ mortality associated with malaria. Achievement of Alma-Ata declaration in terms of RBM is declining; and geo-political zones with previous admirable records are currently less performing. Result shows that improvement in malaria prevalence is associated with baseline knowledge of the situation. Further, reduction in malaria disease level is not really correlated with ITNs ownership, but seems to trend with baseline knowledge of prevalence. Recommendation is therefore made that various levels of government should review their PHC programs. Community based awareness programs to change the attitude of households in the use of ITNs need to be enhanced.

\section{Acknowledgement}

Dr. Phillip Bwititi from Charles Sturt University Australia has kindly supported in editing this manuscript and is hereby acknowledged.

\section{Conflict of Interest}

There is no funding or any conflict of interest to declare.

\section{Ethical approval}

Not required.

\section{References}

1. Giovanella L, Mendonça MHM, Buss PM, et al. (2019) From Alma-Ata to Astana. Primary health care and universal health systems: An inseparable commitment and a fundamental human right. Cadernos de saude publica 35: e00012219.

2. Sanders D, Nandi S, Labonté R, et al. (2019) From primary health care to universal health coverage-one step forward and two steps back. Lancet 394: 619-621.

3. Makaula P, Funsanani M, Mamba KC, et al. (2019) Strengthening primary health care at district-level in Malawi - determining the coverage, costs and benefits of community-directed interventions. BMC Health Serv Res 19: 509.

4. Laverty S (2017) 8 Components of primary health care: Leaf Group Ltd.

5. Odoko JO, Nwose EU, Nwajei SD, et al. (2020) Epidemiology of malaria as it relates to utilization of insecticide treated nets among pregnant women and under five years children in SouthSouth Nigeria. Int J Community Med Public Health 7: 7.

6. Abasiattai AM, Etukumana EA, Umoiyoho AJ (2008) Awareness and practice of malaria prevention strategies among pregnant women in Uyo, South South Nigeria. The Internet Journal of Gynecology and Obstetrics 11: 1-6.

7. Ebomwonyi A, Omoregie AO, Noutcha MAE, et al. (2015) Trend in malaria incidence rates (2006-2013) in Edo State, Nigeria. IJTDH 7: 40-48.

8. Nigeria National Malaria Control Programme, Federal Ministry of Health (2012) Progress \& impact series country reports n. 4: Focus on Nigeria: World Health Organization.

9. Okoh CE, Duru CB, Awunor NS, et al. (2013) Awareness, ownership and utilization of insecticide treated nets in Abavo community of Delta State. Nigerian journal of medicine 22: 326-331.

10. (2011) United States Embassy in Nigeria. Nigeria malaria fact sheet.

11. Okunlola OA, Oyeyemi OT (2019) Spatio-temporal analysis of association between incidence of malaria and environmental predictors of malaria transmission in Nigeria. Scientific reports 9: 17500 .

12. World Health Organization (2012) The Ottawa Charter for Health Promotion.

13. Odoko JO, Nwose EU, Nwajei SD, et al. (2020) Primary healthcare on utilization of insecticide treated nets among pregnant mothers and carers of children in South-South Nigeria. Clinical Medical Reviews and Reports 3.

14. Ankomah A, Adebayo SB, Arogundade ED, et al. (2014) The effect of mass media campaign on the use of insecticide-treated bed nets among pregnant women in Nigeria. Malar Res Treat 2014: 694863.

15. Alenoghena I, Aigbiremolen A, Abejegah C, et al. (2014) Primary health care in Nigeria: Strategies and constraints in implementation. International Journal of Community Research 3: 74-79.

16. Auta A (2012) Demographic factors associated with insecticide treated net use among Nigerian women and children. $\mathrm{N} \mathrm{Am} \mathrm{J}$ Med Sci 4: 40-44.

17. Snow RW, Marsh K (2010) Malaria in Africa: Progress and prospects in the decade since the Abuja declaration. Lancet 376: 137139. 
Citation: Odoko JO, Nwose EU, Nwajei SD, et al. (2021) Alma Ata Declaration and Malaria Prevention: Ten Years Narrative Review of landmark Achievement on Use of Insecticide Treated Nets (ITNS) Among Pregnant Mothers and Children Under Five in Nigeria. Ann Public Health Reports 5(1):193-200

18. Rugemalila JB, Wanga CL, Kilama WL (2006) Sixth Africa malaria day in 2006: How far have we come after the Abuja Declaration? Malaria journal 5: 102.

19. Ejembi J, Ajumobi O, Ibrahim MS, et al. (2018) Predictors of insecticidal net use among internally displaced persons aged 6-59 months in Abuja, Nigeria. The Pan African medical journal 29: 136.

20. Clark H, Coll-Seck AM, Banerjee A, et al. (2020) A future for the world's children? A WHO-UNICEF-Lancet-Commission. The Lancet 395: 605-658.

21. USAID (2019) President's Malaria Initiative Nigeria: Malaria Operational Plan FY 2019.

22. Uzochukwu B, Onwujekwe O, Mbachu C (2015) Implementing the basic health care provision fund in Nigeria: A framework for accountability and good governance.

23. Mittelmark MB, Kickbusch I, Rootman I, et al. (2017) Health promotion. In: Quah SR, International encyclopedia of public health ( $2^{\text {nd }}$ edn). Academic Press, Oxford, P: 450-462.

24. Kumar S, Preetha GS (2012) Health promotion: An effective tool for global health. Indian journal of community medicine 37: 5-12.

25. World Health Organization (2018) World malaria day 2018: Ready to beat malaria.

26. World Health Organization (2019) The E-2020 initiative of 21 malaria-eliminating countries: 2019 progress report.

27. World Health Organization (2020) World malaria day 2020.

28. Odoko JO, Nwose EU, Igumbor EO (2018) Evaluation of utilization of insecticide treated nets among pregnant women in Bayelsa State of Nigeria: A case study of Sagbama community. Int J Res Med Sci 6: 2571-2577.

29. Chukwuocha UM, Dozie IN, Onwuliri CO, et al. (2010) Perceptions on the use of insecticide treated nets in parts of the Imo River Basin, Nigeria: Implications for preventing malaria in pregnancy. African journal of reproductive health 14: 117-128.

30. Anna van Eijk M, Hill J, Noor AM, et al. Prevalence of malaria infection in pregnant women compared with children for tracking malaria transmission in sub-Saharan Africa: A systematic review and meta-analysis. The Lancet Global health 3: e617-e628.

31. Griffiths MJ, Ndungu F, Baird KL, et al. (2001) Oxidative stress and erythrocyte damage in Kenyan children with severe Plasmodium falciparum malaria. Br J Haematol 113: 486-491.

32. Mwendera CA, de Jager $C$, Longwe $H$, et al. (2017) Malaria research in Malawi from 1984 to 2016: A literature review and bibliometric analysis. Malaria journal 16: 246.

33. Yaya S, Uthman OA, Amouzou A, et al. (2018) Use of intermittent preventive treatment among pregnant women in Sub-Saharan Africa: Evidence from malaria indicator surveys. Tropical medicine and infectious disease 3: 18.

34. Balami AD, Said SM, Zulkefli NAM, et al. (2018) Effects of a health educational intervention on malaria knowledge, motivation, and behavioural skills: A randomized controlled trial. Malaria journal 18: 41.
35. Ebuka U (2005) Draft health promotion policy for Nigeria: Federal Ministry of Health.

36. Onwujekwe O, Uzochukwu B, Ezumah N, et al. (2005) Increasing coverage of insecticide-treated nets in rural Nigeria: Implications of consumer knowledge, preferences and expenditures for malaria prevention. Malaria journal 4: 29.

37. National Population Commission - NPC Nigeria, ICF (2019) Nigeria demographic and health survey 2018 Abuja Nigeria, Rockville Maryland USA.

38. Visa TI, Ajumobi O, Bamgboye E, et al. (2020) Evaluation of malaria surveillance system in Kano State, Nigeria, 2013-2016. Infect Dis Poverty 9: 15.

39. Kilian A, Koenker H, Baba E, et al. (2013) Universal coverage with insecticide-treated nets - applying the revised indicators for ownership and use to the Nigeria $\mathbf{2 0 1 0}$ malaria indicator survey data. Malaria journal 12: 314.

40. Alawode OA, Chima V, Awoleye AF (2019) Household characteristics as determinants of ownership of mosquito nets in urban households in Nigeria. Scientific African 6: e00156.

41. Oresanya OB, Hoshen M, Sofola OT (2008) Utilization of insecticide-treated nets by under-five children in Nigeria: Assessing progress towards the Abuja targets. Malaria journal 7: 145.

42. Owens S (2015) Malaria and the millennium development goals. Archives of disease in childhood 100: S53.

43. Oleribe OO, Taylor-Robinson SD (2016) Before Sustainable Development Goals (SDG): Why Nigeria failed to achieve the Millennium Development Goals (MDGs). The Pan African medical journal 24: 156.

44. Maduka O (2018) End malaria for good: A review of current strategies and future novelties for malaria elimination in Nigeria. Malaria World Journal 9: 1-4.

45. World Health Organization (2018) World malaria report.

46. Brieger B (2019) Nigeria's 2018 demographic and health survey: Malaria situation.

47. Bagcchi S (2017) Progress on malaria stalls amid decline in funding. BMJ 359: 5645.

48. Brieger W (2018) Malaria: Rocking or rolling back? African Health 40: $16-19$.

49. Pearson B (2018) Alma Ata rebrands itself to reflect the great Almaty! African Health 40: 3.

50. Madanitsa M, Kalilani L, Mwapasa V, et al. (2016) Scheduled intermittent screening with rapid diagnostic tests and treatment with dihydroartemisinin-piperaquine versus intermittent preventive therapy with sulfadoxine-pyrimethamine for malaria in pregnancy in Malawi: An open-label randomized controlled trial. PLoS Med 13: e1002124.

51. Uzochukwu BSC, World Health Organization (2017) Primary health care systems (PRIMASYS): Case study from Nigeria Geneva. 